\title{
ADOPCIÓN DE MENORES COLOMBIANOS POR PAREJAS EXTRANJERAS DEL MISMO SEXO: UNA PERSPECTIVA DESDE EL RÉGIMEN COLOMBIANO
}

Juan Carlos Rodríguez Flórez

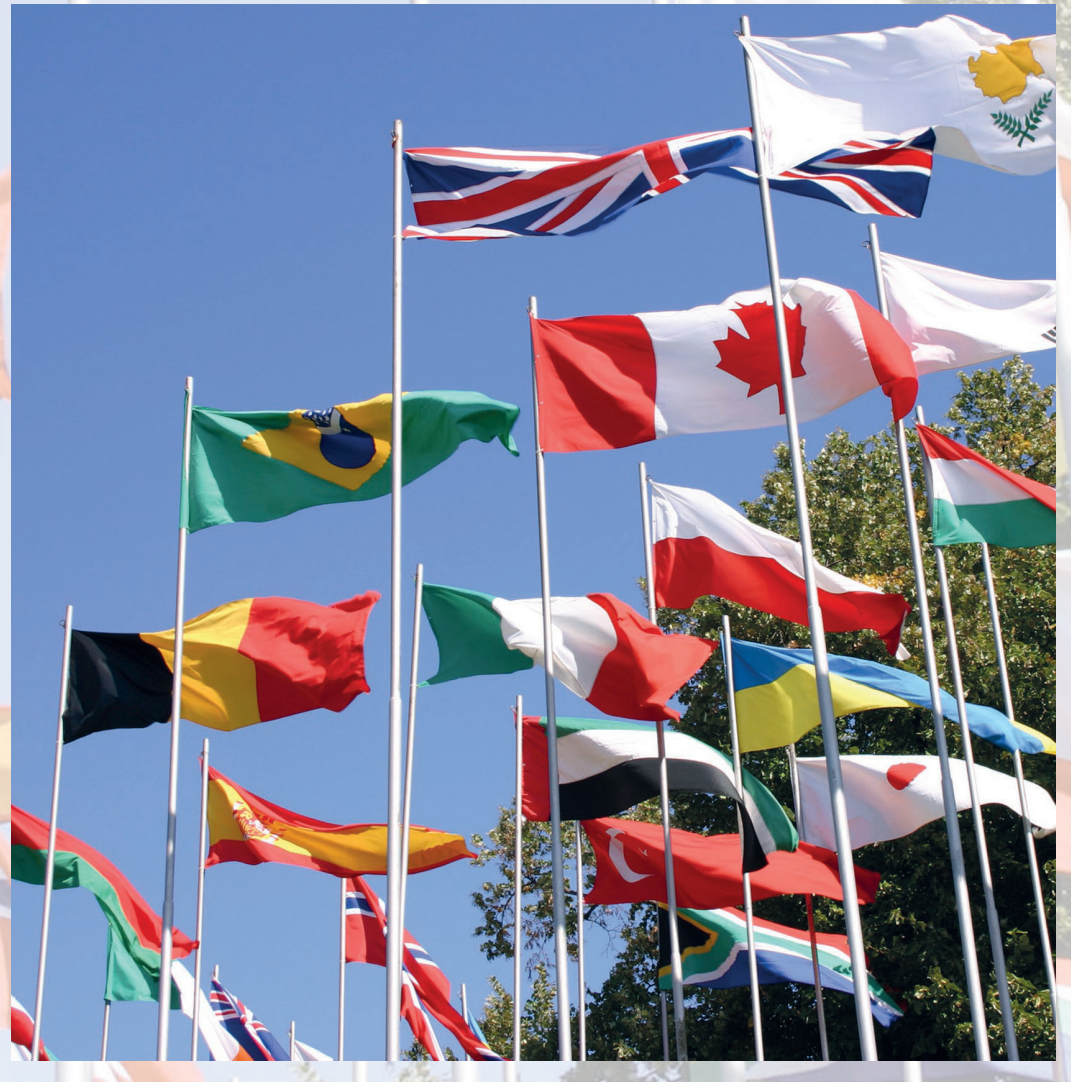





\title{
ADOPCIÓN DE MENORES COLOMBIANOS POR PAREJAS EXTRANJERAS DEL MISMO SEXO: UNA PERSPECTIVA DESDE EL RÉGIMEN COLOMBIANO
}

\author{
Juan Carlos Rodríguez Flórez \\ Universidad Católica de Colombia
}

\section{Resumen}

En el presente artículo de investigación se expone el escaso progreso y la carencia en nuestro ordenamiento jurídico acerca de la regulación de la adopción internacional, específicamente sobre el cambio sociojurídico respecto al matrimonio entre parejas del mismo sexo, pues al endilgarse la igualdad entre uniones heterosexuales y homosexuales, se abre una gran brecha para el derecho y es saber si las parejas del mismo sexo pueden adoptar o no. Ello porque es necesario que no se vean menoscabados los derechos fundamentales de los menores y apegarse al interés superior otorgado por la Carta Política. Más adelante se analizará la adopción en el ámbito del derecho internacional: el derecho fundamental del interés superior del menor y estándar mínimo (derechos y garantías), así como el marco legal de dicha figura jurídica en la jurisprudencia colombiana y en los convenios internacionales. Por último se hará una acotación de la actitud que deben asumir los Estados, en especial Colombia, frente a la adopción de menores por parejas del mismo sexo.

Palabras clave: adopción, interés superior y estándar mínimo, ordenamiento jurídico, nacionalidad, menor, niño, niña o adolescente.

El autor: estudiante de X semestre de Derecho de la Universidad Católica de Colombia, asistente del semillero de Derecho privado y propiedad intelectual, adscrito al Centro de Investigaciones Sociojurídicas de la Universidad Católica de Colombia (Cisjuc). Correo electrónico: jcrodriguez36@ ucatolica.edu.co, juan.rodriguezfl@gmail.com

Recibido: 9 de agosto de 2017 Evaluado: 15 de enero de 2018 Aceptado: 1 de marzo de 2018 


\title{
ADOPTION OF COLOMBIAN MINORS BY FOREIGN SAME-SEX PARTNERS: A PERSPECTIVE FROM THE COLOMBIAN SYSTEM
}

\author{
Juan Carlos Rodríguez Flórez \\ Universidad Católica de Colombia
}

\begin{abstract}
This research article presents the scant progress and deficiency in our legal system regarding the regulation of international adoption and, more specifically, the legal-social change regarding same-sex marriage, since by imposing equality amongst heterosexual and homosexual marriages, a great breach opens up for the law, which is to decide whether same-sex couples can or cannot adopt. This is because it is necessary that the fundamental rights of minors are not undermined, while uphold the best interest principle defended by the Constitution.

Similarly, it analyzes adoption in the field of International Law, studying, first, the fundamental right of the best interest of the minor and the standard minimum (rights and guarantees), as well as the legal status of this legal figure in Colombian jurisprudence and in international agreements. Finally, the text will examine the attitude that States, especially Colombia, should take regarding the adoption of minors by same-sex couples.
\end{abstract}

Keywords: adoption, best interest and standard minimum, legal system, nationality, minor, child or teenager.

Author: Tenth semester law student at the Universidad Católica de Colombia, assistant in the research incubator in private law, affiliated to the Socio-Legal Research Center at the Universidad Católica de Colombia (Cisjuc).Email: jcrodriguez36@ucatolica.edu.co,juan.rodriguezfl@gmail.com

Received: August 9, 2017; evaluated: January 15, 2018; accepted: March 1, 2018 


\section{Introducción}

Para empezar, es esencial conceptualizar el término de adopción y su regulación en el ordenamiento jurídico colombiano. Primero haremos referencia a la definición general otorgada por la Real Academia de la Lengua Española, que señala que adoptar es "Tomar legalmente en condición de hijo al que no lo es biológicamente".

Desde una perspectiva jurídica se ha evidenciado que dicha noción ha sufrido una serie de transformaciones debido a los cambios sociales que surgen de forma natural en una cultura; tal concepto debe ir de la mano con la situación fáctica y la normatividad vigente que regule el proceso en espacio, tiempo y lugar. Por tal razón, la adopción ya no se encuentra en un plano restringido a parejas heterogéneas, en aras de garantizar que personas en condiciones diferentes, como los solteros o uniones del mismo sexo que deseen asumir una relación paternofilial y brindar al menor de edad el amparo y el cuidado de los que carecen por abandono, violencia, desplazamiento forzado, etc.

La figura de la adopción provoca tensión en grupos influyentes del Estado, en cuanto a si es viable o no permitir que las parejas del mismo sexo puedan adoptar, pues por una parte debe salvaguardarse el interés superior del menor y esta es la postura de quienes afirman que no debe aceptarse; por otra parte están quienes argumentan que los niños residentes en los lugares dispuestos por el ICBF no cuentan con las mejores garantías y en otros casos cumplen la mayoría de edad sin ser adoptados, hechos que se sustentan en el derecho que tienen los niños, niñas y adolescentes a conformar una familia y al libre desarrollo de la personalidad, entre otros. ${ }^{2}$

Como se ha dicho, el acto jurídico de adopción ha ido evolucionando de la mano del reconocimiento de los derechos y las garantías constitucionales otorgados a las minorías sociales, como es el caso de parejas conformadas por personas del mismo sexo, quienes han encontrado en la máxima Corporación Constitucional la defensa y protección a sus derechos, al tomar como referentes países con un espectro más amplio basado en la materialización de la dignidad humana, la igualdad y la libertad en todas en sus expresiones.

Real Academia Española, "Adoptar" en Diccionario de la Real Academia Española, http://dle.rae.es/?id=0oKpOJX (acceso marzo 5, 2017).

2 Diana María Martínez Pinzón y Simón Felipe Valenzuela Motta, "El derecho constitucional del menor a tener una familia y a no ser separado de ella" (Tesis de pregrado, Pontificia Universidad Javeriana, s. f), 15. 
Este artículo contiene un breve análisis de la regulación normativa colombiana actual, sus posibles avances — mostrados en pronunciamientos constitucionales que se han convertido en hitos- y la visión que ha surgido en la población colombiana. Todo ello con el fin de vislumbrar cuál es la probabilidad real de que tal derecho sea otorgado a parejas del mismo sexo, las consecuencias y los impactos que podrían ocasionarse a los derechos de los menores de edad dados en adopción.

Con el presente trabajo se pretende responder el siguiente interrogante: ies posible en Colombia la adopción de menores de edad por parte de parejas del mismo sexo o no se ha avanzado en el reconocimiento de tales derechos conforme al ordenamiento jurídico del país?

\section{Tesis}

En comparación con países de la región, como Uruguay, en el ordenamiento jurídico colombiano respecto a la adopción de menores de edad por parte de parejas homosexuales nacionales o extranjeras el progreso es leve, pues carece no solo de la normatividad pertinente, sino de los lineamientos básicos que otorguen una respuesta clara a la controversia entre el interés superior del niño y el derecho a la igualdad en un proceso de adopción entre las parejas homosexuales y las heterosexuales.

En cuanto a la adopción de parejas extranjeras en Colombia, pese a que en el país de origen pueda haber un reconocimiento de derechos a las parejas homosexuales respecto a ella, cuando se tramite en el territorio colombiano, las normas que regirán el proceso serán las de este país, por lo que muchos encontrarán situaciones que aparentemente limitan su derecho, pero en realidad Colombia busca proteger a los menores de edad que se encuentran bajo su cuidado.

\section{Adopción internacional en el territorio colombiano}

La legislación colombiana se ha ocupado de regular en términos generales los procedimientos que deben seguirse en un proceso de adopción, por medio de la Ley 1098 de 2006 que indica: "[... la la adopción es principalmente y por excelencia, una medida de protección a través de la cual, bajo la suprema vigilancia del Estado, se establece de manera irrevocable la relación paterno filial entre personas que no la 
tienen por naturaleza". ${ }^{3}$ Hermenéuticamente puede destacarse el carácter garantista que pretende dar el Legislador, al utilizar un lenguaje neutro respecto al sexo y a la orientación sexual de los aspirantes a convertirse en padres adoptantes.

La misma Ley fijó los requisitos generales que se tienen en cuenta en el momento de seleccionar a los adoptantes:

En primera medida la capacidad:

[...] presupuesto indispensable para asumir responsablemente la crianza de un hijo. Como segundo requisito, la ley no solo impone que la persona sea capaz sino que haya alcanzado una edad mínima de 25 años. El tercer requisito consiste en que el adoptante tenga por lo menos quince (15) años más que la persona a ser adoptada, con lo cual se pretende que no exista una brecha generacional tan amplia con implicaciones negativas en el desarrollo psicomotriz, emocional y social del menor. Finalmente, el cuarto requisito tiene que ver con la idoneidad física, mental, moral y social del adoptante, suficiente para suministrar al niño, niña o adolescente un entorno adecuado y estable para su desarrollo integral. ${ }^{4}$

De ahí puede inferirse la búsqueda del Legislador de condiciones dignas de crecimiento para el adoptado en razón de las cualidades de los adoptantes, desligadas de la orientación sexual de los mismos, pues no la halla relevante.

Según expertos, para que la adopción sea exitosa, además del cumplimiento de los requisitos esbozados, se requiere una serie de procesos de adaptación al nuevo entorno familiar tanto para los adoptantes como para los adoptados. Tal acondicionamiento dependerá, a grandes rasgos, de la edad del menor de edad y los impactos psicosociales que haya tenido que enfrentar; en casos de adopción internacional, la adaptación también obedecerá al acompañamiento constante debido al cambio sociocultural que implica una nueva la cultura, el idioma y los otros elementos que surgen de esta relación. ${ }^{5}$

\footnotetext{
Colombia, Congreso de la República, Ley 1098, "Por la cual se expide el Código de la infancia y la adolescencia" (Bogotá: Diario Oficial No. 46.446, 8 de noviembre de 2006), art. 61.

4 Colombia, Corte Constitucional, Sentencia C-071 de 18 de febrero de 2015, M. P. Jorge Iván Palacio Palacio.

5 Alejandra Solíz Madríz y José Pablo Montoya Calvo, "Proceso de adaptación de personas costarricenses menores de edad, ubicadas en adopción en España”, Acta Colombiana de Psicología 10, núm. 1 (2007): 120.
} 
Tanto para los adoptantes internacionales como para los connacionales surge la obligación de ceñirse a la normatividad colombiana, porque a ella deberán acogerse quienes deseen adoptar un menor de edad que se encuentre en ese Estado, pues según lo sustentado en la Convención de La Haya, tendrán que regirse por los preceptos normativos del país donde el niño, la niña o adolescente (en adelante, NNA) tenga su origen.

Doctrinaria y jurisprudencialmente se ha considerado a la adopción como una medida para restablecer el derecho de los NNA a tener una familia y es el Instituto Colombiano de Bienestar Familiar (en adelante, ICBF) el que ostenta la calidad de máxima autoridad central en materia de adopción; los programas que se desarrollen en torno a ella serán las aprobadas por él y lo ejecutarán las autoridades que él autorice. $^{6}$

La adopción de los NNA en estado de adoptabilidad declarado por el defensor de Familia del ICBF, bien sea por sus condiciones o por autorización expresa de sus padres biológicos en la que se evidencia de manera inequívoca su consentimiento, debe ser un acto idóneo constitucionalmente. Además, debe reflejar la legalidad y la trasparencia de los procedimientos y velar porque la asesoría sobre las consecuencias jurídicas y psicosociales que pueden acarrear su decisión sea suficiente. ${ }^{7}$

Los padres biológicos podrán emitir su consentimiento una vez haya pasado un mes desde la fecha del parto y podrá ser revocado durante el mes siguiente a su otorgamiento. ${ }^{8}$

El proceso de adopción debe surtir dos etapas: la primera es administrativa y se adelanta ante el ICBF con el propósito de que se declare que el NNA es adoptable; la segunda es judicial, pues será necesario que esta sea declara por el juez de Familia mediante sentencia debidamente ejecutoriada en la que se establezca la relación paternofilial. $^{9}$

Colombia, Congreso de la República, Ley 1098, arts. 62 y 73.

Colombia, Congreso de la República, Ley 1098, arts. 62 y 66

Colombia, Congreso de la República, Ley 1098, art. 66.

Intituto Colombiano de Bienestar Familiar [ICBF], "Regulación de la adopción de menores en Colombia", https://www.oas.org/dil/esp/Regulacion_de_la_adopcion_de_menores_Colombia.pdf (acceso mayo 12, 2017). 
El Comité de Adopción de las regionales y seccionales del ICBF seleccionan la familia colombiana o extranjera adoptante y los NNA adoptables que se asignarán. ${ }^{10}$ En todo caso se preferirán a las familias colombianas que a las extranjeras y, si solo hay extranjeras, se dará preferencia a las de los Estados parte de la Convención de La Haya u otros convenios celebrados de la misma índole. Este Comité no podrá entregar a los NNA cuando no se cumplan los requisitos ${ }^{11}$ contemplados en el Artículo 68.

La legislación colombiana, en especial la Ley 1098 de 2006, ha fijado los requerimientos mínimos que debe cumplir quien aspire a convertirse en adoptante de un menor de edad colombiano:

(i) Ser capaz, (ii) haber cumplido 25 años de edad, (iii) tener mínimo 15 años más que el adoptable, (iv) estar en capacidad de garantizar la idoneidad física, mental, moral y social suficiente para suministrar una familia adecuada y estable al NNA. ${ }^{12}$

Por otro lado, también ha definido las calidades particulares que deben demostrar los aspirantes, mediante el respectivo instrumento público:

Pueden adoptar: (i) Las personas solteras, (ii) los cónyuges conjuntamente, (iii) los compañeros permanentes conjuntamente cuando demuestren una convivencia ininterrumpida de mínimo dos (2) años, (iv) el guardador al pupilo o ex pupilo una vez aprobadas las cuentas de su administración,, (v) el cónyuge o compañero permanente, al hijo del cónyuge o compañero, que demuestre una convivencia ininterrumpida de por lo menos dos (2) años.

Adicional a toda la regulación prevista, en Colombia se debe seguir el procedimiento promulgado por el ICBF: ${ }^{13}$

1. Cuando la familia que quiera adoptar se encuentre en un territorio diferente al colombiano, deberá iniciar un proceso de evaluación y preparación, conforme a la regulación prevista en el país en donde se encuentre. En estos casos regirán

Colombia, Congreso de la República, Ley 1098, art. 73.

Colombia, Congreso de la República, Ley 1098, arts. 71 y 73.

Colombia, Congreso de la República, Ley 1098, art. 68.

Intituto Colombiano de Bienestar Familiar [ICBF], "Procedimientos para las familias colombianas y extranjeras residentes en el exterior que desean adoptar en Colombia", http://www.icbf.gov.co/portal/page/portal/ Descargas1/Guiaadopcion.pdf (acceso mayo 14, 2017). 
los tratados y convenios internacionales que hayan sido ratificados por Colombia en torno a la adopción.

2. Si el país en donde reside la familia tiene autoridad central, autoridad competente u organismos acreditados, conforme al Convenio de La Haya "Relativo a la protección del niño y a la cooperación en materia de adopción internacional", esta señalará el trámite y los requisitos para iniciar el proceso de adopción.

3. Si el país en el que reside la familia no forma parte del Convenio de La Haya, deberá contactar a las agencias autorizadas por el ICBF o a las autoridades oficiales competentes (el listado se encuentra en la página web).

4. Si la familia reside en Estados Unidos, por lo menos uno de los solicitantes debe ser nacional de ese país.

5. Cuando la familia que está radicada en otro país quiere adoptar por medio de una de las instituciones autorizada por el ICBF, debe enviar la solicitud a la institución o directamente al Instituto y diligenciar el formulario para ese fin junto con los demás documentos.

Una vez señalados los requisitos básicos del proceso de adopción, se destaca lo reiterado por la Corte Constitucional: "[...] la adopción de niños por personas con orientación sexual diversa, en general, y por parejas del mismo sexo, en particular, no afecta por sí misma el interés superior del menor", ${ }^{14}$ siempre y cuando el cumplimiento minucioso de los requisitos se haga presente, pues son estos los que mitigarán los riesgos de vulneración de los derechos fundamentales de NNA.

\section{Adopción por parejas del mismo sexo en Colombia}

Abordar el tema de la adopción ejercida por parejas del mismo sexo no es una tarea fácil, pues pese al reconocimiento mundial de muchos derechos, aún se mantienen algunos tabúes respecto a las libertades en el ejercicio de dichos derechos.

El avance que se ha hecho frente al reconocimiento de los derechos de parejas del mismo sexo, hoy conocidos como la comunidad LGBTI (lesbianas, gais, bisexuales, transgénero e intersexuales) ha sido un poco lento y por la vía jurisprudencial,

14 Colombia, Corte Constitucional, Sentencia C-071 de 18 de febrero de 2015. 
no por la legislativa, como debiera haber sido por tratarse de un Estado social de derecho. ${ }^{15}$

En vista de ello mencionaremos algunas sentencias de la Corte Constitucional que se han referido al tema, en particular en desarrollo de la tutela judicial efectiva, ${ }^{16}$ como guardiana de la integridad y supremacía de la Constitución ${ }^{17}$ para dar cumplimiento a derechos constitucionales como el acceso a la administración de justicia, ${ }^{18}$ principio de igualdad, ${ }^{19}$ el libre desarrollo de la personalidad ${ }^{20}$ y a la intimidad. ${ }^{21}$

En Colombia, las parejas del mismo sexo eran sancionadas. En el Código Penal de 1936 se consideraban delito las expresiones amorosas por parejas del mismo sexo en público, con sustento en el menoscabo de la moral; en 2001 tal situación cambió y se estableció como una causal de mayor punibilidad la discriminación por razón de la orientación sexual.

\section{La Corte Constitucional y la garantía de derechos para parejas del mismo sexo}

El desarrollo jurisprudencial se ha convertido en el mecanismo idóneo para reivindicar derechos de un grupo poblacional tenido como minoría, lo que ha permitido que adquieran un papel importante dentro de la sociedad. Veremos tal desarrollo en algunas sentencias:

- Sentencia T-594 de 1993. Por primera vez se permitió el cambio de nombre por uno un nombre del otro sexo, reconociendo que cada persona tiene sus convicciones y pensamientos. ${ }^{22}$

- Sentencia T-539 de 1994. Se ampara la no discriminación por ser homosexual, derecho que se tiene por el hecho de ser persona humana. ${ }^{23}$

15 Carolina Forero Barón y Diana Elvira Cárdenas, "Perspectiva de los derechos de las parejas del mismo sexo en Colombia en la jurisprudencia de la Corte Constitucional", Estudios de Derecho y Gobierno 2, núm. 2 (2009): 102.

16 República de Colombia, Constitución Política (Bogotá: Legis, 1991), art. 86.

17 República de Colombia, Constitución Política, art. 241.

18 República de Colombia, Constitución Política, art. 229.

19 República de Colombia, Constitución Política, art. 13.

20 República de Colombia, Constitución Política, art. 16.

21 República de Colombia, Constitución Política, art. 15.

22 Colombia, Corte Constitucional, Sentencia T-594 de 15 de diciembre de 1993, M. P. Vladimiro Naranjo Mesa.

23 Colombia, Corte Constitucional, Sentencia T-539 de 30 de noviembre de 1994, M. P. Vladimiro Naranjo Mesa. 
- Sentencia C-098 de 1996. Se salvaguarda de la vulneración de derechos como a la educación (no ser expulsado), a la libre opción sexual y al trabajo. ${ }^{24}$

- Sentencia C-481 de 1998. En el trabajo se deja de considerar la homosexualidad como causal de mala conducta y falta disciplinaria. ${ }^{25}$

- Sentencia T-1096 de 2004. Se busca garantizar protección a quienes se encuentran en centros penitenciarios. ${ }^{26}$

- Sentencias C-814 de 2001, T-725 de 2007 y T-856 de 2007. Se reconoce el derecho a afiliar a la pareja del mismo sexo al Plan obligatorio de salud como beneficiaria. ${ }^{27}$

- Sentencia C-075 de 2007. Es de gran importancia, pues se otorgó vida jurídica a estas parejas, al reconocer que la unión marital de hecho debía ser tanto para parejas heterosexuales como homosexuales. Además, dentro de los salvamentos se reconoce la falta de pronunciamiento sobre la adopción por parte de parejas del mismo sexo, ya que es un campo sin legislar. ${ }^{28}$

- Sentencia C-789 de 2007. Determinó la obligatoriedad a dar alimentos a la pareja del mismo sexo. ${ }^{29}$

- Sentencia C-336 de 2008. Se reconoció el derecho a la pensión a la pareja del mismo sexo cuando cumpla los requisitos de ley. ${ }^{30}$

- Sentencia C-029 de 2009. En ese año los avances fueron más notorios. Se declaró patrimonio familiar, posibilidad de demandar por alimentos, mayor

24 Colombia, Corte Constitucional, Sentencia C-098 de 7 de marzo de 1996, M. P. Eduardo Cifuentes Muñoz.

25 Colombia, Corte Constitucional, Sentencia C-481 de 9 de septiembre de 1998, M. P. Alejandro Martínez Caballero

26 Colombia, Corte Constitucional, Sentencia T-1096 de 4 de noviembre de 2004, M. P. Manuel José Cepeda Espinosa.

27 Colombia, Corte Constitucional, Sentencia C-814 de 2 de agosto de 2001, M. P. Marco Gerardo Monroy Cabra; Sentencia T-725 de 13 de septiembre de 2007, M. P. Catalina Botero Marino; Sentencia T-856 de 12 de octubre de 2007, M. P. Humberto Antonio Sierra Porto.

28 Colombia, Corte Constitucional, Sentencia C-075 de 7 de febrero de 2007, M. P. Rodrigo Escobar Gil.

29 Colombia, Corte Constitucional, Sentencia C-789 de 20 de septiembre de 2007, M. P. Nilson Pinilla Pinilla.

30 Colombia, Corte Constitucional, Sentencia C-336 de 16 de abril de 2008, M. P. Clara Inés Vargas Hernández. 
punibilidad en casos de violencia intrafamiliar, acceso a subsidios familiares y de vivienda, entre otros. ${ }^{31}$

Sin embargo, como ya se ha mencionado, este es un tema desarrollado jurisprudencialmente y por esta razón nos detendremos a analizar una de las últimas sentencias: la C-863 de 2015, en la cual la Corte Constitucional debía decidir una demanda contra algunos segmentos normativos, contenidos en los Artículos 64, 66 y 68 del Código de la Infancia y la Adolescencia (Ley 1098 de 2006) y 1 de la Ley 54 de 1990.

Estas normas versan sobre los efectos jurídicos de la adopción, el consentimiento para la misma, los requisitos para adoptar y los elementos constitutivos de la unión marital de hecho. A discreción de los accionantes, las normas señaladas excluyen la posibilidad de que los niños sean adoptados por parejas conformadas por personas del mismo sexo. Los demandantes cuestionaron dichas disposiciones, en esencia, por vulnerar el derecho a la igualdad y el interés superior de los niños que permanecen en situación de adoptabilidad, al limitar sin justificación suficiente el universo de familias que pueden adoptarlos. ${ }^{32}$

También adujeron que hubo una omisión relativa del Legislador, violatoria del interés superior de los niños, porque la ley no consagró con claridad una regulación para la adopción por parejas del mismo sexo, lo cual supone una desprotección de la niñez. Por último, observaron que existe una interpretación dominante en la Administración pública (ICBF y Procuraduría General de la Nación) orientada a desproteger a los niños, pues reduce el universo de familias potencialmente adoptantes, en tanto excluye a las parejas del mismo sexo en detrimento de los derechos de los niños.

El órgano de cierre comenzó por precisar que la decisión reciente sobre la materia, contenida en la Sentencia C-071 de 2015, no impide un pronunciamiento sobre las normas demandadas. Ese fallo solo hizo tránsito a cosa juzgada relativa, como ya se había referido, por cuanto se centró en el examen de dos problemas jurídicos, alusivos a los derechos de igualdad y a la familia de las parejas del mismo sexo, pero no a los derechos de los niños desde la perspectiva del principio constitucional del interés superior del menor bajo la guía de la Constitución Política (en adelante,

31 Colombia, Corte Constitucional, Sentencia C-029 de 28 de enero de 2009, M. P. Rodrigo Escobar Gil.

32 Colombia, Corte Constitucional, Sentencia C-071 de 18 de febrero de 2015. 
$\mathrm{CP}$ ) y sobre este planteamiento se sopesan tales derechos de los prohijados por el Estado en relación con sujetos de especial protección como los NNA. ${ }^{33}$ Constató entonces que en la Sentencia C-071 de 2015 la Corte analizó si las normas sobre adopción vulneraban el derecho a la igualdad de las parejas del mismo sexo ${ }^{34} \mathrm{y}$ desconocían también el derecho de las parejas del mismo sexo a constituir familia. ${ }^{35}$

En esa ocasión, la Corte decidió inhibirse respecto al cargo de vulneración del interés superior del menor, por ineptitud de la demanda (con salvamento de voto de un magistrado). En contraste, la Corte verificó que la demanda se dirigiera adecuadamente contra las mismas normas, pero con un enfoque constitucional diferente, en la medida en que centra la discusión en torno al interés superior de los niños. ${ }^{36}$ En el presente caso, la decisión de fondo (habilitar la adopción de niños por parejas del mismo sexo en virtud del interés superior del niño) tuvo como base los siguientes argumentos:

En primer lugar, la Corte señaló que los estudios científicos y las pruebas aportadas al proceso demostraban con solidez que la adopción por parejas del mismo sexo no generaba afectaciones en el desarrollo integral de los niños o que no estaba acreditado ningún perjuicio a los niños que vivían con parejas del mismo sexo. Aun cuando algunas intervenciones indicaban que los resultados no eran definitivos, la Corte verificó que no se refutaron las conclusiones prevalecientes ${ }^{37}$ y la objeción planteada fue inaceptable a la luz de la Constitución, por cuanto afirmaba que la homosexualidad era considerada como una patología, lo cual ha sido desvirtuado.

En segundo lugar, la Sala Plena resaltó que, según la Constitución, los tratados internacionales sobre derechos humanos, la jurisprudencia internacional y la jurisprudencia de esa Corte, la orientación sexual de una persona o su sexo no eran, por sí mismos, indicadores de falta de idoneidad moral, física o mental para adoptar; de tal modo, impedir que un niño tuviera una familia únicamente por la orientación sexual o el sexo de una persona o de una pareja representaba una restricción inaceptable de los derechos del niño y era contrario a su interés superior, protegido por la Constitución y los instrumentos que se integran a ella.

\footnotetext{
República de Colombia, Constitución Politica, art. 44.

República de Colombia, Constitución Política, art. 13.

República de Colombia, Constitución Política, art. 42.

República de Colombia, Constitución Politica, art. 44.

Colombia, Corte Constitucional, Comunicado No. 50 (Bogotá, 4 de noviembre de 2015).
} 
En tercer lugar, la Corte reconoció que una lectura conforme con la Constitución indicaba que, desde la perspectiva de la protección al interés superior del niño, la Ley debía entenderse como neutra frente al sexo de las parejas y a la orientación sexual de quienes las conforman.

En cuarto lugar, la Corte advirtió que, en vista de que no se acreditaba de manera concluyente que los menores de edad sufrieran o pudieran sufrir algún tipo de afectación en su desarrollo armónico e integral por el hecho de ser adoptados o crecer en el entorno de una familia conformada por parejas del mismo sexo, excluir a estas últimas del universo de potenciales adoptantes implicaba una limitación del derecho de los niños a tener una familia y no ser separados de ella, que afecta injustificada, irrazonable y desproporcionadamente su interés superior. ${ }^{38}$

En quinto lugar, la Sala Plena de la Corte verificó y reafirmó que tenía competencia y legitimidad para intervenir en la resolución de este caso. Esto no solo porque la Constitución así lo reconoció expresamente en el Artículo 241, sino además porque se trataba de proteger derechos de población vulnerable, como los niños en situación de adoptabilidad, frente a una interpretación de la Ley que no era conforme con el principio de interés superior de los NNA, en un contexto en el cual los niños eran una población desaventajada en términos representativos, cuyos derechos debía proteger el juez al margen de la decisión de las mayorías políticas. Es en estos casos, para garantizar los derechos de grupos vulnerables y sin representación democrática específica, que se justifica la función de control constitucional a la actividad del Legislador.

La Corte aclaró que cualquier proceso de adopción debía estar siempre dirigido a garantizar el interés superior del menor de edad y al restablecimiento de sus derechos y, por tanto, en todo caso era deber del Estado verificar, conforme a la Constitución y en los términos de esa Sentencia, si se cumplían los demás requisitos establecidos en el ordenamiento jurídico. La Corte quiso resaltar que las dudas y los temores acerca de si la sociedad estaba preparada para asumir esta decisión no se disipaban al negar una inocultable realidad, sino al enfrentar sus desafíos.

Por las anteriores razones, la Corte resolvió declarar la exequibilidad condicionada de las normas impugnadas, en el sentido de que "en virtud del interés superior del menor, dentro de su ámbito de aplicación están comprendidas también las parejas

38 República de Colombia, Constitución Política, art. 44. 
del mismo sexo que conforman una familia". ${ }^{39}$ De tal forma, el ordenamiento constitucional no excluye que los niños sean adoptados por parejas del mismo sexo y formen una familia.

Aunado a lo anterior, en aras de velar por el interés superior del menor, se deben ver las condiciones de quien quiere asumir el papel de adoptante, con el fin de que NNA tengan una familia, que puede ser conformada por una pareja homosexual que reúna las condiciones exigidas, que tenga la capacidad económica y brinde amor, educación, protección, valores, principios y bienestar, puesto que los homosexuales no son personas desequilibradas mentalmente. ${ }^{40}$

\section{Derecho comparado con respecto a la adopción por parejas del mismo sexo}

Hay diversidad de países que han acogido la adopción de NNA por parejas del mismo sexo; sin embargo, no todos lo han hecho en las mismas condiciones. Algunos de ellos son: Holanda, Suecia, Canadá, Inglaterra y Gales, España, Bélgica, Islandia, Uruguay, México, Escocia, Noruega, Finlandia, Argentina, Brasil, Dinamarca, Irlanda del Norte, Francia, Sudáfrica, Estados Unidos y Austria, entre otros.

Con la finalidad de hacer un estudio comparado, solo se revisarán los países más relevantes por sus aportes y trascendencia sociojurídica.

[...] las principales alegaciones en contra parten del pensamiento de que la convivencia de un menor con homosexuales puede resultar desfavorable para su desarrollo social y psicológico. Básicamente se resumen a cuatro posiciones: 1. riesgo de que el menor pueda sufrir una mala influencia; 2 . incapacidad de los homosexuales de ser buenos padres o buenas madres; 3 . riesgo del menor sufrir violencia sexual paterna o materna; 4. difícil inclusión del menor en el medio debido al reproche social en torno a la homosexualidad de sus padres; y, 4. riesgo del menor sufrir violencia sexual paterna o materna. ${ }^{41}$

9 Colombia, Corte Constitucional, Sentencia C-071 de 18 de febrero de 2015.

40 Unicef, "Adopción internacional”, serie Innocenti Digest núm. 4, ed. Unicef (Siena: Autor, 1999), 14-15.

41 Miguel Antonio Silveira Ramos, "La cuestión de la adopción por parejas homosexuales", Âmbito Jurídico, VIII, núm. 21 (2005), http://www.ambito-juridico.com.br/site/index.php?n_link=revista_artigos_leitura\&artigo_ id=581 (acceso junio 17, 2017). 
No obstante, Holanda, Bélgica y España, países en donde ya se han implementado las mencionadas políticas, la experiencia evidencia la debilidad de los argumentos en contra.

Estos países que aprobaron la adopción de los NNA por parejas homosexuales tuvieron una transformación de principios legales y morales, debido a que el derecho es cambiante y se acopla o acomoda a los cambios sociales; no obstante, aun cuando la han permitido, siguen velando por la protección del interés superior del menor.

[... . país que ya en 1998 había puesto en marcha registros municipales de parejas de hecho, con independencia de su orientación sexual, y que en septiembre de 2000 aprobó una ley que autorizaba el matrimonio civil a personas del mismo sexo (siempre que una de ellas fuera de nacionalidad holandesa o tuviera su residencia fijada en Holanda), les permitía adoptar niños (a condición de que éstos fueran holandeses) y sentaba pautas para el divorcio. Dicha ley entró en vigor el 1 abril de 2001. ${ }^{42}$

Holanda, pionero en implementar políticas públicas tendientes al reconocimiento de derechos en iguales condiciones que permiten que las parejas del mismo sexo adopten, ha sido contundente en los requisitos que debe cumplir una pareja homosexual para adoptar en ese país: solo personas holandesas (al menos una) o que tengan su residencia habitual en ese país podrán adoptar a los NNA de la misma nacionalidad; mientras, pese a que Colombia ha especificado los requerimientos de adopción — sin excepción de la calidad del adoptante-, no ha facilitado la adopción legal por parejas del mismo sexo sino mediante fallos de tutela de la Corte Constitucional.

Un segundo ejemplo es Uruguay. Allí se establece que las parejas del mismo sexo tienen la posibilidad de adoptar en las mismas condiciones que las parejas heterosexuales. Dicha norma fija un procedimiento de jurisdicción voluntaria, en el que se tendrá que hacer la solicitud en un juzgado letrado de Familia del domicilio del adoptante; en Colombia, por el contrario, debe hacerse en el lugar en donde se encuentra el menor, llamado también "foro especial". Se integra también al Instituto del Niño y Adolescente del Uruguay y, en caso de que se oponga, deberá

42 Ramos, "La cuestión de la adopción por parejas homosexuales". 
hacerse un trámite contencioso mediante el proceso extraordinario contemplado en el Código General del Proceso. ${ }^{43}$

El tercer ejemplo es Canadá, que posee un sistema federal en el que depende de cada Estado o provincia determinar si es pertinente o no permitir la adopción por parejas del mismo sexo o familias homoparentales.

Otra muestra es el caso español. En 2013, después de la aprobación de la ley que permitía la unión legal "civil" de parejas conformadas por dos personas del mismo género, se permitió de manera absoluta la adopción de niños rusos por estas parejas, con remisión expresa a la Ley 21 de 1987 —que modificó el Código Civil en materia de adopción—y a la Ley 35 de 1988 — que introdujo al sistema normativo la reglamentación de las técnicas de reproducción asistida-. Así se abrió paso, aunque solo parcialmente, a la homoparentalidad desde el ordenamiento jurídico y se amplió de manera discrecional la posibilidad de adoptar por las personas solteras, en cuyo trámite se ocultaba su orientación sexual.

En España, en particular en el País Vasco, Cataluña, Aragón y Navarra, se reguló la adopción conjunta por parejas del mismo sexo y se definieron medidas como el acogimiento de menores de edad, para garantizar el interés superior del menor de manera "transitoria". ${ }^{4}$

Por otra parte, desde una perspectiva psicológica, existen diversas posturas en torno al cuestionamiento de si los homosexuales pueden ejercer el rol de adoptantes en escenarios donde los menores pueden ser expuestos a situaciones de juzgamiento y estigmatización, lo que conllevaría a que el proceso de adaptación del que ya hablamos se torne más complejo, pues se saldría de una órbita jurídica a una psicológica; en últimas, se generaría un conflicto social, ya que el NNA incluso se vería empujado a mentir para ocultar la condición de sus padres y evitar ser rechazado. ${ }^{45}$

La adopción por parejas del mismo sexo es objetada por gran parte de la sociedad, debido a las posturas encontradas entre la moral religiosa y la aplicabilidad de esta

43 Uruguay, Cámara de Senadores, Ley 18.590, "Código de la niñez y la adolescencia. Se modifican disposiciones relativas a adopción" (Montevideo: Diario Oficial No. 27.837, 16 de octubre de 2009), art. 142.

44 Helena Soleto, Las medidas provisionales en los procesos de familia (Valencia: Tirant lo Blanch, 2002), 39

45 Ana María De Oliveira Nusdeo y Carlos Alberto de Salles, "Adopción por homosexuales. El discurso jurídico" en Derechos y sexualidades. Seminario en Latinoamérica de Teoría Constitucional y Política, ed., coord. o comp. SELA (Brasil: Libraria, 2009), 52. 
figura dentro del ordenamiento jurídico; como es natural, muchos ponen resistencia con fundamento en la moral colectiva manejada en un Estado laico como Colombia.

En su momento el papa Juan Pablo II rechazó tal idea, pues sostenía que los NNA serían expuestos a un ambiente no sano para su desarrollo y que la unión de dos personas del mismo sexo no podía ser considerada como una familia.

Álvaro Ferrer, abogado y académico de la Pontificia Universidad Católica de Chile, señaló:

[...] la más grave consecuencia (de la adopción gay) es el atentado contra la dignidad de los niños. Ellos son así considerados como cosas y objetos, como simples medios para satisfacer deseos y aspiraciones de adultos, como requisitos del avance de una agenda basada en la reivindicación ideológica. ${ }^{46}$

La posición de este jurista tiene un fundamento moralista, ya que primero muestra que la adopción no puede ser un medio para que quienes tienen orientación sexual diferente satisfagan su deseo de tener una familia como la tendrían una pareja heterosexual o atender sus derechos y, por otra parte, expresa que no se acepta la idea de que se acoplen figuras como estas a la realidad social, debido a que se terminaría desnaturalizando el fin de la figura misma.

Más adelante abordaremos el estado actual de la adopción por parejas del mismo sexo. Sin embargo, es de resaltar que el reconocimiento de estos derechos aumenta cada día, pues las leyes deben ir en consonancia con los fenómenos y las realidades sociales. Por ello, en casos específicos y con efectos interpartes, la Corte Constitucional ha permitido la adopción a parejas del mismo sexo en el caso en que uno de los miembros de la pareja sea el padre consanguíneo. La razón por la que se ha tutelado la adopción por parejas del mismo sexo ha sido porque el derecho es progresivo y, así como se ha evidenciado un avance en el matrimonio entre parejas LGTBI, también se lucha por la adopción igualitaria.

Bárbara Bustamante, "¿Qué hay detrás de la adopción gay? Lo explica un experto jurista”, https://www. aciprensa.com/noticias/que-hay-detras-de-la-adopcion-gay-un-experto-explica-una-dura-realidad-41483 (acceso julio 19, 2017). 


\section{6. Ámbito de aplicación de convenios y tratados de adopción}

Los NNA tienen una protección especial que recibe el nombre de "interés superior del menor" y que, a la luz del derecho internacional, ha presentado una evolución normativa, porque se han venido implementando varios mecanismos protectores de las violaciones de sus derechos, para que hoy exista una regulación mediante convenios y tratados internacionales de la adopción de menores, los cuales serán abordados de una forma sucinta.

Primero se hará un bosquejo de la Declaración de los derechos del niño, de 1959. Este es un avance real y materializado avance en pro de la protección de los niños y fue aprobado por la ONU en noviembre de ese año. La Declaración instituye unos derechos mínimos de los que debe disfrutar todo niño de los Estados parte en la Convención.

Como primera medida, exhorta a los Estados a que prevean los mecanismos necesarios para que todo niño disfrute de protección especial y además tengan oportunidades y servicios que les permitan desarrollarse en forma normal, en condiciones de libertad y dignidad; para que tenga un nombre y una nacionalidad desde su nacimiento; para que goce de los beneficios de seguridad social y reciba tratamiento, educación y cuidados especiales si tiene algún padecimiento, con el fin de que crezca en un ambiente de afecto y seguridad; para que reciban educación y puedan:

[...] figurar entre los primeros en recibir protección y socorro en casos de desastre; para que se le proteja contra cualquier forma de discriminación, a la par de que sea educado en un espíritu de comprensión, tolerancia, amistad entre los pueblos, por la paz y la fraternidad universal. ${ }^{47}$

Esta Declaración, que proclama los derechos de NNA, también insta a padres, adultos, organizaciones y autoridades a que reconozcan estos derechos y luchen por su observancia. ${ }^{48}$ En Colombia, el Congreso de la República ratificó la Convención por medio de la Ley 12 de 1991 y la Asamblea Nacional Constituyente incluyó el criterio y los principios de protección integral a la niñez en su doble dimensión: como garantía de los derechos de NNA y como protección en condiciones especialmente

\footnotetext{
47 Paola Andrea Duque Camacho y Lina Margarita Ramírez Torres, "La adopción una medida de protección, garantia, y restablecimiento de derecho de los niños y las niñas en Colombia” (Tesis de pregrado, Pontificia Universidad Javeriana, 2010), 10.

48 Unicef, Declaración de los derechos del niño (Washington, 20 de noviembre de 1959).
} 
difíciles. Ello se encuentra consagrado en los Artículos 13, 44, 45, 50 y 67 de la Constitución Política.

El segundo avance en materia de defensa de los derechos de los NNA fue la Convención internacional sobre derechos del niño, de 1989, la cual constituye un compromiso de la comunidad internacional para la protección de sus derechos civiles, políticos, económicos, sociales y culturales. Esta Convención es un tratado internacional que obliga a los Estados parte a garantizar a todos los niños el acceso a la educación y atención médica; condiciones para desarrollar plenamente su personalidad, habilidades y talentos; un ambiente propicio para crecer con felicidad, amor y comprensión; información sobre la manera como pueden exigir sus derechos y ser parte del proceso en una forma participativa.

Respecto al tema en examen, la Convención es clara al manifestar en relación con la adopción: "[...] aquellos países en los cuales se reconozca o se permita, ésta se realizará teniendo como consideración primordial el interés superior del niño y se velará porque las adopciones sean legalmente autorizadas garantizando el bienestar del niño con su nueva familia". ${ }^{49}$ El interés superior del niño al que hace referencia la Convención es un concepto que busca describir de manera general el "bienestar del menor".

Este marco general de la Convención otorgó a la legislación colombiana las bases jurídicas para el desarrollo normativo, hasta el punto de aplicar la figura de la adopción como una medida de protección y restablecimiento de derechos de NNA del país.

Por otra parte, si bien es cierto que se regularon unos mecanismos internacionales de protección para los NNA, también se abrió una brecha respecto a la adopción internacional y se "configura cuando los adoptantes y los adoptivos no tienen la misma nacionalidad o cuando el domicilio habitual de los adoptantes y del niño se encuentran en países diferentes". ${ }^{50}$

Con el avance legislativo y doctrinario se privilegia la regulación de la adopción, y se enfoca a que quienes adopten sean nacionales y, como excepción, sean extranjeros

\footnotetext{
Agencia de la ONU para los refugiados [Acnur], "El interés superior del niño", http://www.refworld.org/ cgi-bin/texis/vtx/rwmain/opendocpdf.pdf?reldoc=y\&docid=50acb9c52 (acceso julio 22, 2017).

50 Myriam Patricia Barona Muñoz, La adopción y la familia (Bogotá: Arte Libro Impresiones, 2006), 11.
} 
si y solo si el niño no puede ser adoptado en el país de origen y tampoco puede permanecer en el seno de su familia biológica.

En un primer momento, son la familia, el Estado y la sociedad los que deben velar por los derechos de los menores de edad y porque crezcan en ambientes propicios para su desarrollo integral. La comunidad internacional es la última que debe ser llamada a solucionar este tipo de problemas cuando las obligaciones no sean cumplidas. $^{51}$

Como tercer aporte con respecto a la evolución del marco jurídico de la adopción internacional se encuentra la Convención interamericana sobre conflictos de leyes en materia de la adopción. Se destaca el esfuerzo en pro de la delimitación, promoción y protección de los derechos de los NNA mediante las Conferencias especializadas interamericanas de derecho internacional privado (Cidip). ${ }^{52}$

Respecto a este avance jurídico regional sobresalen la Convención interamericana sobre conflictos de leyes en materia de adopción de menores, aprobada en La Paz el 24 de mayo de 1984 (Cidip-III) y la Convención interamericana sobre tráfico internacional de menores, aprobada en Ciudad de México el 18 de marzo de 1994 $\left(\right.$ Cidip-V). ${ }^{53}$

La Convención interamericana sobre conflictos de leyes en materia de adopción de menores (en adelante, Convención interamericana) tuvo su origen en una propuesta del Instituto Interamericano del Niño y, según González, insistió en la necesidad de regular las adopciones internacionales ante el aumento de fenómenos como el tráfico ilegal y la migración internacional de los NNA. ${ }^{54}$ El texto finalmente adoptado responde a un sistema mixto o bipartito de ley uniforme y conflictual, en el que se contempla tanto la competencia judicial internacional y el derecho aplicable; con

51 Ricardo Rueda, "La adopción desde sus raíces hasta hoy" (Tesis de pregrado, Universidad Nuestra Señora del Rosario, 2000), 12.

52 José Luis Siqueiros, "La cooperación judicial internacional", Jurídica. Anuario del Departamento de Derecho de la Universidad Iberoamericana, núm. 19 (s. f.): 51.

53 Antonia Durán Ayago, "El interés del menor en el conflicto de civilizaciones: elementos para su concreción en un contexto intercultural" en El derecho de familia ante el siglo XXI: aspectos internacionales, coords. Alfonso Luis Calvo Caravaca y Esperanza Castellanos Ruiz (Madrid: Colex, 2004), 295.

54 Nuria González Martín, El derecho de familia en un mundo globalizado (Ciudad de México: Porrúa-UNAM, 2007), 89. 
él no se trata de uniformar las leyes de los Estados, sino de ponerlas en armonía recurriendo básicamente a reglas formales de derecho internacional privado. ${ }^{55}$

Esta Convención: i) define la adopción internacional con base en la residencia habitual en Estados distintos entre adoptante y adoptado, ${ }^{56}$ ii) diferencia entre adopción internacional y adopción por extranjeros, para evitar el encubrimiento de ilícitos ${ }^{57}$ iii) incluye la adopción plena y abre la posibilidad de la adopción simple; ${ }^{58}$ iv) instituye la ley aplicable a los derechos sucesorios del adoptado y del adoptante ${ }^{59}$ y v) amplía el concepto del vínculo del adoptado con su familia de origen e indica que este queda disuelto.

Además, la Convención interamericana es de cobertura bipartita, pues da respuesta tanto a la competencia judicial internacional como al derecho aplicable y deja fuera al reconocimiento y ejecución de sentencias en el extranjero. Todo ello se enmarca en un ámbito de aplicación que se divide en tres: material personal, espacial y temporal; tres requisitos acumulativos que debemos analizar en cada uno de los convenios y que deben existir para aplicar dicha Convención en un determinado país. ${ }^{60}$

Los tres elementos (personal, espacial y temporal) son importantes; sin embargo, debido a que se analiza la aplicabilidad en el sistema jurídico colombiano, no se ahondará en el ámbito de aplicación espacial. En este ámbito de aplicación espacial nos encontramos ante un silencio convencional en el que nos inclinamos por pensar que estamos ante una convención interpartes y la deducción viene del Artículo 1, que establece: "[...] el adoptante (o adoptantes) tengan su domicilio en un Estado parte y el adoptado su residencia habitual en otro Estado parte" ${ }^{61}$ Hay una exigencia respecto a la relación entre Estados parte y se elimina la posibilidad de aplicación erga omnes. ${ }^{62}$

\footnotetext{
Didier Opertti, Comentarios a la Convención interamericana sobre conflictos de leyes en materia de adopción de menores (Montevideo: Instituto Interamericano del Niño, 1986), 150.

56 Organización de Estados Americanos [OEA], Convención interamericana sobre conflictos de leyes en materia de adopción de menores (La Paz, 24 de mayo de 1984), art. 1.

57 OEA, Convención interamericana sobre conflictos de leyes en materia de adopción de menores, arts. 20 y 25.

58 OEA, Convención interamericana sobre conflictos de leyes en materia de adopción de menores, arts. 1 y 2.

59 OEA, Convención interamericana sobre conflictos de leyes en materia de adopción de menores, art. 11.

60 Elva Leonor Cárdenas Miranda, "Adopción internacional" en Estudios sobre adopción internacional, coords. Nuria González Martín y Andrés Rodríguez Benot (Ciudad de México: Universidad Nacional Autónoma de México, 2001), 39.

61 OEA, Convención interamericana sobre conflictos de leyes en materia de adopción de menores, art. 1.

62 Vásquez Pando, F. A. "Régimen jurídico de la adopción internacional de menores. Derechos de la niñez", (México, UNAM Instituto Investigaciones Jurídicas, 1990).
} 
Debido a los vacíos normativos, era necesaria una norma general y vinculante que diera solución al problema; por ello, la Convención Interamericana fue y es una solución efectiva, porque fijó el procedimiento para la adopción, así como los efectos y la norma aplicable para su validez.

La Convención de La Haya, del 29 de mayo de 1993, instituye la protección internacional del menor, al definir con mayor precisión el amparo de los NNA y la cooperación en materia de adopción internacional. Sin embargo, a pesar de la importancia de su contenido, no ha sido ratificada por los países identificados como de destino, lo cual impide su aplicabilidad efectiva. ${ }^{63}$

Esta Convención determina que, por regla general, debe aplicarse la ley interna del país al que pertenecen las autoridades encargadas de autorizar la adopción. Sin embargo, es posible hacer una concesión al principio de la nacionalidad. La Convención es clara al manifestar que las adopciones autorizadas de conformidad con ella deben ser reconocidas de pleno derecho por todos los Estados vinculados, ${ }^{64}$ entre los que se encuentran Australia, Canadá, Chile, Colombia, Alemania, India, Italia, Suiza y Estados Unidos. En Colombia fue ratificado por la Ley 265 de 1996.

\section{Conclusiones}

La adopción internacional por parejas del mismo sexo en Colombia se ha permitido por la vía jurisprudencial y goza de toda legalidad y validez en el ordenamiento jurídico; sin embargo, tales decisiones no son acordes con la realidad social, pues se requiere que el reconocimiento de estos derechos se hiciera por la vía legislativa para que tuvieran aplicabilidad real en el sistema jurídico. Este reconocimiento se enfrenta a la moral social de un país, por lo que en caso de que los adoptantes extranjeros del mismo sexo gocen de un derecho de tal índole en su país de origen y no en Colombia, no se atenta contra sus derechos; pese a que el derecho es una regulación de situaciones universales, es necesario que haya un foro para la ejecución de tales actos y, en este caso, será un foro territorial, que nos indicará que quien pretenda adoptar en un país debe adherirse a las normas de dicho país.

Lázaro Tenorio Godinez, "Matrimonio entre homosexueles y adopción de hijos. Paradigmas por resolver", Revista de Derecho Privado, edición especial (2012): 316.

64 Gonzalo Parra Aranguren, "La Convención de La Haya de 1993 sobre la protección del niño y la cooperación en materia de adopción internacional", Boletín de la Facultad de Derecho, núm. 61 (1994):155-156. 
Dada la complejidad de la figura de la adopción y más aún con el ingrediente normativo llamado "interés superior", poco a poco se vislumbra como un tema de simple ponderación en el que, por una parte, existe la posibilidad de que parejas del mismo sexo puedan adoptar y, por otra, que este derecho sea reservado solo a parejas heterosexuales y ha sido resuelto por distintos sistemas jurídicos que, mediante la facultad legislativa y conforme al contexto social, han permitido o negado la posibilidad de adopción.

La decisión de la aceptación o no de la adopción por parte de parejas del mismo sexo en el ordenamiento jurídico colombiano debe resolverse desde el plano normativo con inclusión de la moral social; para ello, al Legislativo le corresponde zanjar esta disyuntiva, por ser este el representante del pueblo. Pese a que se ha intentado legislar sobre este tema, a la fecha aún no es posible la adopción por parejas del mismo sexo en estricto sentido, sino solo si uno de sus miembros es el padre biológico del menor de edad y adicionalmente por vía de la acción de tutela.

Ante la deferencia que tienen el derecho positivo de los derechos humanos y el ordenamiento nacional por el matrimonio, la defensa férrea — por demás, legítima - de la institución matrimonial y sus ventajas sobre la unión marital de hecho en el régimen patrimonial, es necesario abordar los derechos de las parejas del mismo sexo no a partir del principio de igualdad, sino del deber de las mayorías de reconocer y respetar las diferencias o el derecho de estas parejas a constituir familia mediante un mecanismo que se adapte a sus características.

El derecho y todos los procesos judiciales y administrativos deben ser acordes con las situaciones; por ello, es de especial incidencia el grado de desarrollo del país en donde se pretenda el acceso de parejas del mismo sexo a la adopción, pues el desarrollo va de la mano de nuevas ideas que transforman las figuras tradicionales. Hemos tenido en cuenta casos como los de Holanda y Uruguay, ya que son países que tienen un proceso diferente al colombiano: solo en Holanda el Legislador abrió las puertas para que parejas del mismo sexo adopten, pero en Colombia encontramos que los reconocimientos que se han hecho son muy precarios.

Si se considera que la Constitución es interpretada según intereses particulares, existe la pretensión de consolidar la adopción como un derecho de las parejas homosexuales. En efecto, estas personas, representadas por el grupo LGBTI, asumen que al defender la libertad y la igualdad, la Carta garantiza el acceso a los mismos derechos de cualquier grupo social. Por supuesto, no podemos negar que 
durante mucho tiempo algunas personas han sido señaladas y perseguidas debido a sus orientaciones sexuales y personales y que esta situación sigue presentándose.

No vemos necesario apelar a criterios ideológicos para tomar una decisión sobre la viabilidad de la adopción por parejas conformadas por miembros del mismo sexo; más bien, la defensa universal de los derechos humanos es la que nos sirve de faro para velar por la seguridad del ser humano, en este caso, la seguridad de los NNA y el derecho a desarrollar sus capacidades y su propia personalidad.

\section{Referencias}

Agencia de la ONU para los refugiados [Acnur]. "El interés superior del niño". http://www. refworld.org/cgi-bin/texis/vtx/rwmain/opendocpdf.pdf?reldoc=y\&docid=50acb9c52 (acceso abril 12, 2017).

Barona Muñoz, Myriam Patricia. La adopción y la familia. Bogotá: Arte Libro Impresiones, 2006.

Bustamante, Bárbara. "¿Qué hay detrás de la adopción gay? Lo explica un experto jurista". https://www.aciprensa.com/noticias/que-hay-detras-de-la-adopcion-gay-un-expertoexplica-una-dura-realidad-41483 (acceso julio 19, 2017).

Cárdenas Miranda, Elva Leonor. "Adopción internacional" en Estudios sobre adopción internacional, coordinado por Nuria González Martín y Andrés Rodríguez Benot, 25-47. Ciudad de México: Universidad Nacional Autónoma de México, 2001.

Colombia, Congreso de la República. Ley 1098, "Por la cual se expide el Código de la infancia y la adolescencia". Bogotá: Diario Oficial No. 46.446, 8 de noviembre de 2006.

Colombia, Corte Constitucional. Sentencia T-539 de 15 de diciembre de 1993. M. P. Vladimiro Naranjo Mesa.

Colombia, Corte Constitucional. Sentencia T-594 de 15 de diciembre de 1993. M. P. Vladimiro Naranjo Mesa.

Colombia, Corte Constitucional. Sentencia C-098 de marzo de 1996 de 1996. M. P. Eduardo Cifuentes Muñoz.

Colombia, Corte Constitucional. Sentencia C-481 de 9 de septiembre de 1998. M. P. Alejandro Martínez Caballero.

Colombia, Corte Constitucional. Sentencia C-814 de 2 de agosto de 2001. M. P. Marco Gerardo Monroy Cabra.

Colombia, Corte Constitucional. Sentencia T-1096 de 4 de noviembre de 2004. M. P. Manuel José Cepeda Espinosa.

Colombia, Corte Constitucional. Sentencia C-075 de 7 de febrero de 2007. M. P. Rodrigo Escobar Gil. 
Colombia, Corte Constitucional. Sentencia T-725 de 13 de septiembre de 2007, M. P. Catalina Botero Marino.

Colombia, Corte Constitucional. Sentencia T-856 12 de octubre de 2007. M. P. Humberto Antonio Sierra Porto.

Colombia, Corte Constitucional. Sentencia C-789 de 20 de septiembre de 2007. M. P. Nilson Pinilla Pinilla.

Colombia, Corte Constitucional. Sentencia C-336 de 16 de abril de 2008. M. P. Clara Inés Vargas Hernández.

Colombia, Corte Constitucional. Sentencia C-029 de 28 de enero de 2009. M. P. Rodrigo Escobar Gil.

Colombia, Corte Constitucional. Comunicado No. 50. Bogotá, 4 de noviembre de 2015.

Colombia, Corte Constitucional. Sentencia C-071 de 18 de febrero de 2015. M. P. Jorge Iván Palacio Palacio.

De Oliveira Nusdeo, Ana María y Carlos Alberto de Salles. "Adopción por homosexuales. El discurso jurídico" en Derechos y sexualidades. Seminario en Latinoamérica de Teoría Constitucional y Política, editado, coordinado o compilado por SELA, 40-60. Brasil: Libraria, 2009.

Duque Camacho, Paola Andrea y Lina Margarita Ramírez Torres. "La adopción una medida de protección, garantia, y restablecimiento de derecho de los niños y las niñas en Colombia”. Tesis de pregrado, Pontificia Universidad Javeriana, 2010.

Durán Ayago, Antonia. "El interés del menor en el conflicto de civilizaciones: elementos para su concreción en un contexto intercultural" en El derecho de familia ante el siglo XXI: aspectos internacionales, coordinado por Alfonso Luis Calvo Caravaca y Esperanza Castellanos Ruiz, 295-318. Madrid: Colex, 2004.

Forero Barón, Carolina y Diana Elvira Cárdenas. "Perspectiva de los derechos de las parejas del mismo sexo en Colombia en la jurisprudencia de la Corte Constitucional”. Estudios de Derecho y Gobierno 2, núm. 2 (2009): 97-116.

González Martín, Nuria. El derecho de familia en un mundo globalizado. Ciudad de México: Porrúa-UNAM, 2007.

Intituto Colombiano de Bienestar Familiar [ICBF]. "Procedimientos para las familias colombianas y extranjeras residentes en el exterior que desean adoptar en Colombia". http://www.icbf.gov.co/portal/page/portal/Descargasl/Guiaadopcion.pdf (acceso marzo 5, 2017).

Intituto Colombiano de Bienestar Familiar [ICBF]. "Regulación de la adopción de menores en Colombia". https://www.oas.org/dil/esp/Regulacion_de_la_adopcion_de_menores_Colombia.pdf (acceso julio 29, 2017). 
Martínez Pinzón, Diana María y Simón Felipe Valenzuela Motta. "El derecho constitucional del menor a tener una familia y a no ser separado de ella". Tesis de pregrado, Pontificia Universidad Javeriana, s. f.

Opertti, Didier. Comentarios a la Convención Interamericana sobre conflictos de leyes en materia de adopción de menores. Montevideo: Instituto Interamericano del Niño, 1986. Organización de Estados Americanos [OEA]. Convención interamericana sobre conflictos de leyes en materia de adopción de menores. La Paz, 24 de mayo de 1984.

Parra Aranguren, Gonzalo. "La Convención de La Haya de 1993 sobre la protección del niño y la cooperación en materia de adopción internacional”. Boletín de la Facultad de Derecho, núm. 61 (1994): 155-170.

Ramos, Miguel Antonio Silveira. "La cuestión de la adopción por parejas homosexuales". Âmbito Jurídico, VIII, núm. 21 (2005). http://www.ambito-juridico.com.br/site/index. php?n_link=revista_artigos_leiturakartigo_id=581 (acceso abril 12, 2017).

Real Academia Española. "Adoptar" en Diccionario de la Real Academia Española. http://dle. rae.es/?id=0oKpOJX (acceso marzo 5, 2017).

República de Colombia. Constitución Política. Bogotá: Legis, 1991.

Rueda, Ricardo. "La adopción desde sus raíces hasta hoy". Tesis de pregrado, Universidad Nuestra Señora del Rosario, 2000.

Siqueiros, José Luis. "La cooperación judicial internacional". Jurídica. Anuario del Departamento de Derecho de la Universidad Iberoamericana, núm. 19 (s. f.): 21-56.

Soleto, Helena. Las medidas provisionales en los procesos de familia. Valencia: Tirant lo Blanch, 2002.

Solíz Madríz, Alejandra y José Pablo Montoya Calvo. "Proceso de adaptación de personas costarricenses menores de edad, ubicadas en adopción en España”. Acta Colombiana de Psicología 10, núm. 1 (2007): 111-122.

Tenorio Godinez, Lázaro. "Matrimonio entre homosexueles y adopción de hijos. Paradigmas por resolver". Revista de Derecho Privado, edición especial (2012): 311-326.

Unicef. Declaración de los derechos del niño. Washington, 20 de noviembre de 1959.

Unicef. "Adopción internacional", serie Innocenti Digest núm. 4, editado por Unicef. Siena: Autor, 1999.

Uruguay, Cámara de Senadores. Ley 18.590, "Código de la niñez y la adolescencia. Se modifican disposiciones relativas a adopción”. Montevideo: Diario Oficial No. 27.837, 16 de octubre de 2009.

Vásquez Pando, F. A. "Régimen jurídico de la adopción internacional de menores. Derechos de la niñez”, México, UNAM Instituto Investigaciones Jurídicas, 1990. 